East African Medical Journal Vol. 85 No. 12 December 2008

REPEATABILITY AND VALIDITY OF IUATLD RESPIRATORY QUESTIONNAIRE RESPONSES AS A MEASURE OF ASTHMA IN AN ETHIOPIAN POPULATION

W. Denboba, MPH, School of Public Health, Addis Ababa University, P. O. Box 9086, Addis Ababa, Ethiopia, A. Venn, $\mathrm{PhD}$, J. Britton, PhD, Division of Epidemiology and Public Health, University of Nottingham, City Hospital, Hucknall Road, Nottingham NG5 1PB and G. Davey, MD, School of Public Health, Addis Ababa University, P. O. Box 26905/1000, Addis Ababa, Ethiopia

Request for reprints to: Dr. G. Davey, School of Public Health, Addis Ababa University, P.O. Box 26905/1000, Addis Ababa, Ethiopia

\title{
REPEATABILITY AND VALIDITY OF IUATLD RESPIRATORY QUESTIONNAIRE RESPONSES AS A MEASURE OF ASTHMA IN AN ETHIOPIAN POPULATION
}

\author{
W. DENBOBA, A. VENN, J. BRITTON and G. DAVEY
}

\begin{abstract}
Objective: To assess the repeatability and validity of the IUATLD respiratory symptoms questionnaire in relation to exercise-induced bronchoconstriction or bronchodilator responses in a community in southern Ethiopia.

Design: A case-control study.

Setting: Rural and small town setting in southern Ethiopia, April to May 2006.

Subjects: Two hundred and forty seven adults and children who previously reported wheeze in the past year, and 174 who did not.

Interventions: Administered IUATLD bronchial symptoms questionnaire; standardised free-running exercise test or (for those with airflow obstruction) assessment of bronchodilator response to inhaled salbutamol.

Results: Kappa values for four-week repeatability for the wheeze and asthma questions were $0.61(95 \%$ CI 0.52 to 0.70$)$ and 0.75 (0.63 to 0.87$)$, respectively. Of the 58 people who reported wheeze in 2003 and in April 2006, only five had a positive exercise test or bronchodilator challenge (Positive Predictive Value (PPV) 0.09, 95\% CI 0.01 to 0.22). Of the 12 who reported asthma in 2003 and April 2006, three had a positive result to either to exercise test or bronchodilator challenge test (PPV 0.25, 95\% CI 0.05 to 0.50 ).

Conclusion: Our findings suggest that self-reported wheeze and asthma have good short-term repeatability, but do not closely reflect exercise-induced bronchospasm or bronchodilator responsiveness. The validity of questionnaire methods of studying asthma epidemiology in developing countries needs further investigation.
\end{abstract}

\section{INTRODUCTION}

Studies of asthma aetiology in developing countries have found consistent evidence that self-reported asthma is more prevalent in urbanised than in subsistence populations, but much of this evidence is based on self-reported rather than objectively measured markers of asthma (1-8). However, the recent ISAAC studies $(9,10)$ indicate that the prevalence of asthma has increased substantially in many of the countries in which it was until recently low, and our own study in Butajira did not find evidence of a marked urban-rural difference in prevalence (11).
The validity of results of questionnaire studies depends, among other factors, on the validity of the questionnaire measures used to define disease. Validation of ISAAC and IUALTD questionnaire symptoms against physician diagnosis or bronchial hyperresponsiveness has been carried out in higherincome populations (12-15), but in the context of developing countries it can be extremely difficult, for logistic, cultural and ethical reasons, to use more objective markers of asthma such as airway hyperresponsiveness to validate these measures. In the light of our findings in Butajira we have therefore assessed the validity and repeatability of widely used asthma questions in relation to objective 
measures of exercise-induced bronchoconstriction, or of bronchodilator response in individuals with resting airflow obstruction, in the rural and urban Butajira populations that participated in our earlier studies (11).

\section{MATERIALS AND METHODS}

Study area and source population: Our study sample was selected from participants in a cross-sectional study carried out in 2003 (11) in which questionnaire data were collected from 3485 urban and 4164 rural residents aged five years or more. These survey participants were initially selected from the Butajira Rural Health Programme, a large, dynamic cohort covering over 40,000 people living in ten administrative areas around Butajira, $135 \mathrm{~km}$ south of Addis Ababa (16).

Sampling methods: All respondents to the 2003 survey, aged between 5 and 38 years at the time and who had provided a response to the question "Have you had wheeze or whistling in your chest at any time in the last year?", were eligible for inclusion in the current study. This age range was selected because we considered that it would be difficult to encourage older adults to complete the exercise test, and because it still represented $79 \%$ of the original population studied. Of those who had reported wheeze in 2003, predetermined sample sizes of 180 urban and 180 rural residents were randomly selected, and of those who answered ' $\mathrm{No}^{\prime}$ to this question in 2003, 140 urban residents and 140 rural residents were randomly selected

Sample size calculation: Pre-study sample size calculations showed that 100 urban and 100 rural residents with self-reported wheeze, and the same number withoutself-reported wheeze, would allow us to estimate positive and negative predictive values to within at least $7 \%$ (based on 95\% confidence intervals) and values of kappa as a measure of repeatability to within 0.07 , assuming kappa to be $\geq 0.7$. We estimated that $30 \%$ of previous wheezers would no longer report wheeze, and that $10 \%$ of previous non-wheezers would report wheeze (data based on changes in outcomes observed between 1996 and 1999 in Jimma follow-up studies) $(17,18)$. To allow for this, plus an estimated combined non-trace and non-response rate of $20 \%$ (based on earlier research in the Butajira area) (11), we inflated our samples to 180 with reported wheeze in 2003, and 140 without in each area.

Data collection. In April 2006, the individuals selected were visited in their homes by one of the base enumerators, given basicinformation about the study, and asked for verbal consent backed by a thumbprint if they were willing to take part. Those who agreed to participate were asked to respond to the Amharic translation of the IUATLD questionnaire ('2006a'), asked to make an appointment for the questionnaire to be re-administered within the next four weeks ('2006b'), and invited to attend an exercise test at the health post closest to them. At the health post, the field co-ordinator examined participants to detect occult wheeze, and with one of four trained nurses blind to the questionnaire responses, measured resting heart rate and performed spirometry using a portable turbine spirometer (MicroMedical, UK), calibrated daily. Ambient temperature was measured before each set of tests using a portable thermometer. The best of three spirometer readings was taken, and any individual with baseline forced expiratory volume in one second $\left(\mathrm{FEV}_{1}\right)$ less than 1.5 litres or $60 \%$ predicted, or any other condition precluding an exercise challenge (for example advanced pregnancy, physical disability, visual impairment or mental handicap) was given $200 \mu \mathrm{g}$ salbutamol through a spacer, and had FEV 1 measured 15 minutes later. All other participants performed the exercise challenge which involved six (for children aged 12 or below) or eight minutes (for all other participants) free running around a flat, measured course $(19,20)$, followed by spirometry 5,10 and 15 minutes post exercise. A positive response was defined as either a decrease in $\mathrm{FEV}_{1}$ from baseline of $\geq 15 \%$ at any time post-exercise, or an increase in $\mathrm{FEV}_{1}$ of $\geq 15 \%$ after salbutamol (20).

Data analysis: Data were entered into Epi-Info version 6, and cleaned and analysed in SPSS version 10. Repeatability of the IUATLD wheeze question between the two 2006 time points (2006a and 2006b) was assessed using Cohen's kappa. Longer term 'repeatability' was assessed similarly by comparing responses to the 2003 questionnaire to the first questionnaire administered in 2006 (2006a). Validity of the wheeze question was assessed by computing positive and negative predictive values using a positive response to either the exercise challenge or bronchodilator challenge test as the 'gold standard'. This was done first using only wheeze responses in 2006 (2006a) and then restricting to those with consistent responses at the two time points (2003 and 2006a). Repeatability and validity of the asthma question were assessed by taking the 'positives' to be all those wheezers with reported everhaving asthma, and the 'negatives' to be all 200 non-wheezers plus a random sample of the wheezing non-asthmatics proportionate to that in the 2003 random sample.

Ethical approval: Ethical committees of the Faculty of Medicine, Addis Ababa University, and the Ethiopian Science and Technology Agency gave approval for this study. 
Table 1

Descriptive characteristics of the study sample

\begin{tabular}{|c|c|c|c|c|c|c|c|c|}
\hline & \multicolumn{4}{|c|}{ Repeatability of wheeze question $(n=421)$} & \multicolumn{4}{|c|}{ Validity of wheeze question $(\mathrm{n}=374)$} \\
\hline & \multicolumn{2}{|c|}{ Urban $(n=196)$} & \multicolumn{2}{|c|}{ Rural $(n=225)$} & \multicolumn{2}{|c|}{ Urban $(\mathrm{n}=174)$} & \multicolumn{2}{|c|}{ Rural $(n=200)$} \\
\hline & No. & $(\%)$ & No. & $(\%)$ & No. & $(\%)$ & No. & $(\%)$ \\
\hline Sex, $\%$ men & 81 & 41.3 & 92 & 40.9 & 70 & 40.2 & 85 & 42.5 \\
\hline Age, mean (SD) & 19.5 & 9.23 & 22.8 & 9.81 & 19.4 & 9.34 & 22.8 & 9.93 \\
\hline \multicolumn{9}{|c|}{ Wheeze in the last 12 months } \\
\hline Yes & 41 & 20.9 & 72 & 32 & 39 & 22.4 & 70 & 35 \\
\hline No & 155 & 79.1 & 153 & 68 & 135 & 77.6 & 130 & 65 \\
\hline \multicolumn{9}{|l|}{ Smoking status } \\
\hline Smokers & 9 & 4.6 & 10 & 4.4 & 6 & 3.4 & 10 & 5 \\
\hline Non-smokers & 187 & 95.4 & 215 & 95.6 & 168 & 96.6 & 190 & 95 \\
\hline \multicolumn{9}{|l|}{ Educational status } \\
\hline Formal education & 153 & 78.1 & 97 & 43.1 & 137 & 78.7 & 85 & 42.5 \\
\hline $\begin{array}{l}\text { Illiterate and can only } \\
\text { read and write }\end{array}$ & 43 & 21.9 & 128 & 56.9 & 37 & 21.3 & 115 & 57.5 \\
\hline
\end{tabular}

\section{RESULTS}

Characteristics of participants are shown by area of residence in Table 1. Urban participants were significantly younger and more likely to be formally educated than rural participants. Their baseline $\mathrm{FEV}_{1}$ was lower and their heart rate (as percentage predicted) higher than those of rural participants.

Repeatability of wheeze and asthma questions: Of the 360 subjects who reported wheeze in 2003,247 responded to the questionnaire twice in 2006 (119 urban and 128 rural). Of the 280 without wheeze, 174 completed the questionnaire twice in 2006 (77 urban and 97 rural), thus a total of 421 subjects ( $66 \%$ response) were included in the analysis of wheeze repeatability. Of those who had reported wheeze in $2003,159 / 247(64.4 \%)$ no longer reported wheeze in 2006a, and this was similar in urban and rural participants. The majority of non-wheezers in 2003 still did not report wheeze in 2006a 149/174 (85.6\%), with the remaining $25 / 174$ (14.4\% ) reporting new wheeze (Figure 1). The Kappa value for long-term repeatability was poor for wheeze (Kappa $0.19,95 \%$ CI 0.12 to 0.26 , Table 2), and fair for asthma (Kappa $0.46,95 \%$ CI 0.29 to 0.64 , Table 3). Short-term repeatability was good for the wheeze question (Kappa 0.61,95\% CI 0.52 to 0.70, Table 2), and for the asthma question (Kappa $0.75,95 \%$ CI 0.63 to 0.87, Table 3). All Kappa values were similar among urban and rural participants.

Validation of wheeze and asthma questions: Of the 421 participants who responded to the questionnaire twice (2006a and 2006b), 323 completed the exercise test, 51 subjects were given bronchodilator, and 47 did not do either test (39 did not attend, seven were pregnant, and one was unable to use a spirometer despite repeated training attempts). Of the 374 individuals who contributed to validation of the wheeze and asthma questions, only 16 individuals had positive responses to either challenge: 11 to the exercise test and five to the bronchodilator test (Figure 1). The positive predictive value for the wheezequestion was therefore low (0.07) and only increased slightly when just those with consistent questionnaire responses were considered (PPV=0.09; Table 4). PPV values for the asthma question were higher than for wheeze and again higher if only consistent responses were considered. All negative predictive values were high due to the small numbers of positive 'gold standard' responses (Table 4). 


\section{Figure 1.}

Subjects participating in the repeatability and validity studies

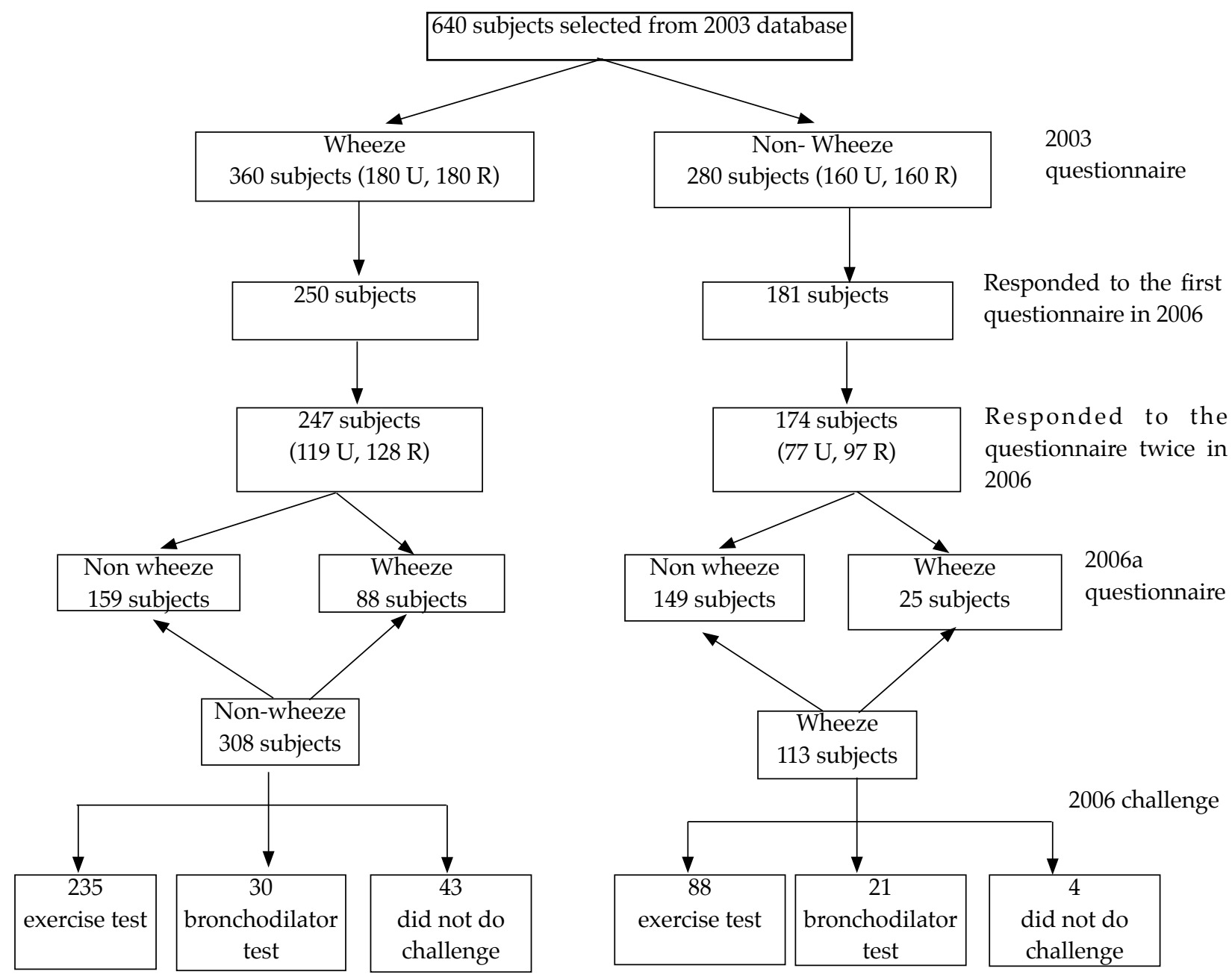

$\mathrm{U}=\mathrm{Urban}$ and $\mathrm{R}=$ Rural

Table 2

Four-week and three-year agreement for wheeze question

Wheeze or whistling in your chest in the last twelve months, 2006a

\begin{tabular}{|c|c|c|c|c|}
\hline & & Yes & No & Total \\
\hline Wheeze or & Yes & 72 & 19 & 91 \\
\hline $\begin{array}{l}\text { whistling in } \\
\text { your chest in }\end{array}$ & No & 41 & 289 & 330 \\
\hline the last twelve & Total & 113 & 308 & 421 \\
\hline $\begin{array}{l}\text { months, } \\
2006 b\end{array}$ & Kappa & $0.61(0.52$ to 0.70$)$ & & \\
\hline Wheeze or & Yes & 88 & 159 & 247 \\
\hline $\begin{array}{l}\text { whistling in } \\
\text { your chest in }\end{array}$ & No & 25 & 149 & 174 \\
\hline the last twelve & Total & 113 & 308 & 421 \\
\hline months, 2003 & Карра & $0.19(0.12$ to 0.26$)$ & & \\
\hline
\end{tabular}


Table 3

Four-week and three-year agreement for asthma question

\begin{tabular}{lllcc}
\hline & \multicolumn{3}{c}{ Ever had asthma, 2006a } \\
& & Yes & No & Total \\
\hline Ever had & Yes & 25 & 6 & 31 \\
asthma, 2006b & No & 9 & 358 & 367 \\
& Total & 34 & 364 & 398 \\
& Kappa & $0.75(0.63$ to 0.87$)$ & 15 \\
Ever had & Yes & 12 & 3 & 371 \\
asthma, 2003 & No & 22 & 349 & 386 \\
& Total & 34 & 352 & \\
& Kappa & $0.46(0.29$ to 0.64) & \\
\hline
\end{tabular}

Table 4

Positive and negative predictive values of wheeze and asthma questions

\begin{tabular}{llll}
\hline Response to & Reference test & $\begin{array}{l}\text { Gold standard } \\
\text { (Exercise test or }\end{array}$ & PPV (95\% CI) \\
Question: & & bronchodilator \\
& & \\
& & \\
& & \\
& &
\end{tabular}

\begin{tabular}{|c|c|c|c|c|}
\hline \multirow{4}{*}{$\begin{array}{l}\text { Have you had } \\
\text { wheeze in the } \\
\text { last } 12 \\
\text { months? }\end{array}$} & \multicolumn{4}{|l|}{$2006 a$} \\
\hline & Yes 109 & Positive 8 & 0.07 (0.02 to 0.12$)$ & \\
\hline & No 265 & Negative 257 & & 0.97 (0.95 to 0.99$)$ \\
\hline & 2003 and 2006a & & & \\
\hline \multirow{7}{*}{$\begin{array}{l}\text { Have you ever } \\
\text { had asthma? }\end{array}$} & Yes 58 & Positive 5 & $0.09(0.01$ to 0.16$)$ & \\
\hline & No 118 & Negative 114 & & $0.97(0.93$ to 1.00$)$ \\
\hline & $2006 a$ & & & \\
\hline & Yes 33 & Positive 4 & 0.12 (0.10 to 0.23$)$ & \\
\hline & $\begin{array}{l}\text { No } 319 \\
2003 \text { and 2006a }\end{array}$ & Negative 310 & & $0.97(0.95$ to 0.99$)$ \\
\hline & Yes 12 & Positive 3 & $0.25(0.05$ to 0.50$)$ & \\
\hline & No 316 & Negative 307 & & 0.97 (0.95 to 0.99$)$ \\
\hline
\end{tabular}

\section{DISCUSSION}

In this remote setting, methacholine or histamine challenge are impractical, since many hamlets are reached only after several hours strenuous walking, so we chose exercise-induced bronchoconstriction as our measure of airway responsiveness. Exercise challenge has been found to be repeatable and highly correlated with histamine challenge in other populations (19), and has also been used in African children $(1,2)$. Prior to the study, we were confident that young Ethiopian adults (who are generally accustomed to physical effort in relation to their daily work) could undertake the measurements. We have shown that it is feasible to conduct spirometry and exercise challenge tests in this Ethiopian population with little familiarity with sophisticated medical tests. Eighty nine per cent of those responding to the questionnaire attended and were able to use the spirometer well enough to perform an exercise test or demonstrate salbutamol reversibility.

\section{Repeatability}

The short-term repeatability of self-reported wheeze in the past year and self-reported asthma was good according to Altman's criteria for Kappa (21) (good defined as Kappa 0.6-0.8). However the three-year repeatability was poor for wheeze (Kappa, 0.19) and fair for asthma (Kappa, 0.46). Changes in responses to symptom-based questions are likely to be partly due to inaccurate responses, but may also reflect true changes in symptom status, particularly when the time period considered is long. In this study, the interval ranged from one to thirty days for the interviews in 2006 and approximately three years between the 2003 and 2006 responses. Variation over a four-week period for a question about wheeze over the past year therefore likely reflects poor questionnaire 
repeatability, whereas variation over a three-year period is likely to also include the effects of true variations in symptoms.

Most people $(64.4 \%)$ in this study who reported wheeze in 2003 no longer reported wheeze three years later, which was considerably more than expected from previous studies in Ethiopia $(17,18)$. Fourteen per cent of previous non-wheezers reported wheeze which was only $4.4 \%$ more than anticipated (18). Responses to questions about 'ever' diagnosis should vary littleover time, yet previous studies have shown considerable variation in responses to such questions over several years (22). Reassuringly in this study, short-term Kappa was higher for the 'asthma ever' question than for the wheeze question.

An international comparison of the repeatability of the IUATLD questionnaire in a clinical population (23), using a two-week interval and a self administered questionnaire found Kappa values ranging from 0.73 to 0.95 (for wheeze) and 0.70 to 1.00 (for asthma) according to study centre, which are comparable with, if slightly higher than, our findings over a four-week period. Another study assessing the repeatability of the IUATLD bronchial symptoms questionnaire in British adults found a Kappa of 0.76 for the wheeze question over a six-week to six-month period (24). Research by Galobardes et al (25) using an interval ranging from 1 to 365 days demonstrated a Kappa of 0.76 for the IUATLD wheeze question when administered by mail and a Kappa of 0.64 when administered by telephone, both of which are higher than the four-week repeatability in this study. This may reflect linguistic or cultural differences concerning recording of or affording importance to dates and the passage of time, both affecting responses to time-bound questions.

Validity: Currently there is no universally accepted gold standard diagnosis for asthma. Previous epidemiological studies to validate asthma questionnaires have utilised bronchial hyper-responsiveness to a range of challenge tests, previously validated questionnaires or physician diagnosis.

This study used bronchoconstriction after exercise or reversibility to bronchodilator as the comparator. Bronchoconstriction after exercise may occur in the absence of symptoms, and not every individual with symptoms of wheeze or atopy has bronchoconstriction after exercise. In addition, questions from the IUATLD questionnaire collect information on symptoms of wheeze over the last 12 months and asthma ever, while exercise testing is an immediate test, the results of which will vary according to individual subjects' airway tone on the day of testing. This may result in poor identification of subjects with mild asthma who do not respond to the exercise challenge on the test day, and thus raise false negative levels.

Research into the predictive value of respiratory symptoms in Swiss subjects aged 18-60 years using the European Center for Respiratory Health Survey (ECRHS) questionnaire found the positive and negative predictive values of the question "Have you had wheeze or whistling in your chest in the last twelve months", against a gold standard of self-reported diagnosis of asthma to be 0.12 and 0.99 respectively, (26) which are very similar to the findings of this study. Validation of the Spanish version of the ISAAC questionnaire in children aged 10-17 years against diagnostic clinical criteria yielded positive and negative predictive values of 0.91 and 0.65 for the wheeze question and 0.91 and 0.98 for the asthma question (27).

In summary, although wehave demonstrated that measuring bronchoconstriction in response to exercise is feasible in this remote developing country setting, very few individuals gave a positive response. The short-term repeatability of the wheeze and asthma questions of this translation of the IUATLD is reasonable, but validity in relation to exercise test or bronchodilator challenge test is poor. Further studies are required to determine whether this poor validity has arisen because exercise-induced bronchoconstriction is itself a poor correlate of asthma in this population, or whether questionnaire measures are unable to detect asthma reliably.

\section{ACKNOWLEDGEMENTS}

To Dr. Kibrebeal Melaku in the preparatory phases of this study.

\section{Competing interests}

The authors declare that they have no personal or financial conflicts of interest that might bias this work.

\section{Role of the funding source}

The study was funded by the Association of Physicians, UK in response to an application outlining the study design. The funding source was not involved in the collection, analysis or interpretation of the data, the writing of the manuscript or the decision to submit the manuscript for publication.

\section{REFERENCES}

1. Keeley, O. J., Neill, P. and Gallivan, S. Comparison of the prevalence of reversible airways obstruction in rural and urban Zimbabwean children. Thorax. 1991; 46: 549-553. 
2. Ng'ang'a, L. W., Odhiambo, J. A., Mungai, M.W., et al. Prevalence of exercise induced bronchospasm in Kenyan school children: an urban-rural comparison. Thorax. 1998; 53: 919-926.

3. Nyan, O.A., Walraven, G. E., Banya, W. A., et al. Atopy, intestinal helminth infection and total serum IgE in rural and urban adult Gambian communities. Clin. Exp. Allergy. 2001; 31: 1672-1678.

4. Huang, S. L., Tsai, P. F. and Yeh, Y. F. Negative association of Enterobius infestation with asthma and rhinitis in primary school children in Taipei. Clin. Exp. Allergy. 2002; 32: 1029- 1032.

5. Medeiros, M., Jr., Figueiredo, J. P., Almeida, M. C., et al.Schistosoma mansoni infection is associated with a reduced course of asthma. J. Allergy. Clin. Immunol. 2003; 111: 947-951.

6. Cooper, P. J., Chico, M. E., Bland, M., et al. Allergic symptoms, atopy and geohelminth infections in a rural area of Ecuador Am. J. Resp. Crit. Care. Med. 2003;168: 313 - 317.

7. Palmer, L. J., Celedon, J. C., Weiss, S. T., et al. Ascaris lumbricoides infection is associated with increased risk of childhood asthma and atopy in rural China. Am. J. Resp. Crit. Care. Med. 2002; 165: 1489-1493.

8. Weinberg, E. G. Urbanization and childhood asthma: An African perspective. J. Allerg. Clin. Immunol. 2000; 105: 224-231.

9. Asher, M. I., Montefort, S., Bjorkstem, B., et al. Worldwide time trends in the prevalence of symptoms of asthma, allergic rhinoconjunctivitis, and eczema in childhood: ISAAC Phases One and Three repeat multi country cross-sectional surveys. Lancet. 2006; 368: 733-743.

10. Pearce, N., Ait-Khaled, N., Beasley, R., et al. Worldwide trends in the prevalence of asthma symptoms: phase III of the International Study of Asthma and Allergies in Childhood (ISAAC). Thorax. 2007; 62: 757-765.

11. Davey, G., Venn, A., Belete, H., et al. Wheeze, allergic sensitization and geohelminth infection in Butajira, Ethiopia. Clin. Exp. Allergy. 2005; 35: 301-307.

12. Gibson, P.G., Henry, R., Shah, S., et al. Validation of the ISAAC video questionnaire (AVQ3.0) in adolescents from a mixed ethnic background. Clin. Exp. Allergy. 2000; 30: 1181-1187.

13. Hong, S. J., Kim, S. W., Oh, J. W., et al. ISAAC video questionnaire (AVQ 3.0) for predicting asthma associated with bronchial hyperreactivity in a group of 13-14 year old Korean schoolchildren. J. Korean Med. Sci. 2003; 18: 48-52.

14. Jenkins, M.A., Clarke, J.R., Carlin, J. B., et al. Validation of questionnaire and bronchial hyperresponsiveness against respiratory physician assessment in the diagnosis of asthma. Int. J. Epidemiol. 1996; 25: 609616.
15. Gruchalla, R. S., Gan, V., Roy, L, et al. Results of an inner-city school-based asthma and allergy screening pilot study: a combined approach using written questionnaires and step testing. Ann. Allergy. Asthma. Immunol. 2003; 90: 491-499.

16. Berhane, Y., Wall, S., Kebede, D., et al. Establishing an epidemiological field laboratory in rural areas - potentials for public health research and interventions. Ethiopian J. Hlth. Dev. 1999; 13: (Special Edition) 1-46.

17. Scrivener, S., Yemaneberhan, H., Zebenigus, M., et al. Independent effects of intestinal parasite infection and domestic allergen exposure on risk of wheeze in Ethiopia: a nested case-control study. Lancet. 2001; 358: 1493-1499.

18. Dagoye, D., Bekele, Z., Woldemichael, K., et al. Wheezing, allergy and parasite infection in children in urban and rural Ethiopia. Am. J. Respir. Crit. Care. Med. 2003; 167: 1369-1373.

19. Haby, M. M., Peat, J.K., Mellis, C. M., et al. An exercise challenge protocol for epidemiological studies of childhood asthma: validity and repeatability. Eur. Resp. J. 1995; 8: 729-736.

20. ATS. Guidelines for methacholine and exercise challenge testing, 1999. Am. J. Resp. Crit. Care. Med. 2000; 161: 309-329.

21. Altman, D. G. PracticalStatistics for Medical Research. Chapman \& Hall, London 1991.

22. Anderson, H. R., Pottier, A. C. and Strachan, D. P. Asthma from birth to age 23: incidence and relation to prior and concurrent atopic disease. Thorax. 1992; 47: 537-542.

23. Burney, P. G. J., Laitinen, L. A., Perdrizet, S., et al. Validity and repeatability of the IUATLD (1984) bronchial symptoms questionnaire: an international comparison. Eur. Resp. J. 1989; 2: 561-568.

24. Burney, P. G. J., Chinn, S., Britton, J. R., et al. What symptoms predict the bronchial response to histamine? Evaluation in a community survey of the bronchial symptoms questionnaire (1984) of the International Union Against Tuberculosis and Lung Disease. Int. J. Epidemiol. 1989; 1: 164-173.

25. Galobardes, B., Sunyer, J., Anto, J. M., et al. Effect of the method of administration, mail or telephone, on the validity and reliability of a respiratory health questionnaire. The Spanish Centers of the European Asthma Study. J. Clin. EpidemioI. 1998; 51: 875-881.

26. Sistek, D., Tschopp, J. M., Schindler, C., et al. Clinical diagnosis of current asthma: predictive value of respiratory symptoms in the SAPALDIA study. Eur. Resp. J. 2001; 17: 214-219.

27. Mata Fernandez, C., Fernandez-Benitez, M., Perez Miranda, M., et al. Validation of the Spanish version of the Phase III ISAAC questionnaire on asthma. J. Invest Allergol. Clin. Immunol. 2005; 15: 201-210. 
East African Medical Journal Vol. 85 No. 12 December 2008

EVALUATION OF ASSESSMENT INSTRUMENTS USED ON CHILDREN PRESENTING WITH ALTERED LEVEL OF CONSCIOUSNESS

P. W. Njuguna, MBChB, MMed, (Paed), P. O. Box 230-80108, Kilifi, Kenya, D. P. Oyatsi, MBChB, MMed (Paed) (UoN), Dip. Neurology (London), Lecturer and M. English, MA, MD, MRCPCH, Honorary Lecturer, Department of Paediatrics and Child Health, College of Health Sciences, University of Nairobi, P. O. Box 19676-00202, Nairobi, Kenya

Request for reprints to: Dr. P. W. Njuguna, P.O. Box 230-80108, Kilifi, Kenya

\title{
EVALUATION OF ASSESSMENT INSTRUMENTS USED ON CHILDREN PRESENTING WITH ALTERED LEVEL OF CONSCIOUSNESS
}

\author{
P. W. NJUGUNA, D. P. OYATSI and M. ENGLISH
}

\begin{abstract}
Objective: To compare current care with a proposed gold standard (formal coma scale use) for assessment of children presenting with altered consciousness.

Design: A prospective study.

Setting: Kenyatta National Hospital, Nairobi, Kenya.

Subjects: One hundred and seventy children consecutively admitted to the hospital. Main outcome measures: Proportion of children assessed using a formal coma scale (gold standard) while presenting with altered consciousness.

Results: Findings revealed that only $8 \%$ of children were assessed using the formal coma scale at admission. The level of neurological deficit was described using general and potentially misleading descriptive terms rather than formal coma scales.

Conclusion: The use of a formal coma scale and relevant simple investigations were seldom used. The quality of care of children admitted to the hospital with altered consciousness standard would benefit from defining and implementing management guidelines (protocols).
\end{abstract}

\section{INTRODUCTION}

Critically ill children often present with some degree of altered consciousness and coma is a neurological emergency associated with high morbidity and mortality (1). The causes of non-traumatic coma are varied. Delayed recognition and treatment of the causes of altered consciousness may lead to far reaching effects including permanent neurological sequelae.

The clinician's first response to a child presenting with altered consciousness should be to follow standard resuscitation proceduresinitially focusing on the airway, breathing and circulation as hypoxemia, hypercarbia, acidosis and ischaemia may all cause or contribute to neurological impairment (2).

After assessing and managing any problems identified in the $\mathrm{ABC}$ sequence the specific degree of neurological deficit should be determined. This may be done using one of the rapid triage scales such as the simple Alert, responds to Voice, responds to Pain, or Unresponsive (AVPU) scale. However standard, moreinformative scales such as the modified Glasgow coma scale or the Blantyre coma scale should then be used for the regular assessment of children with altered consciousness particularly in tertiary or teaching hospitals. The Glasgow coma scale (GCS), was initially developed for use in adults with head injury but has been modified to allow for assessment of children as the modified Glasgow coma scale (3). The wide applicability and predictive value of the Glasgow coma scale has resulted in it becoming the standard method taught in medical training for the assessment of the level of consciousness.

The national standards of care in hospitals in Kenya, summarised in a handbook "Clinical Guidelines" by the Ministry of Health, recommend the use of a formal coma scale (the Glasgow coma scale) in assessment of level of consciousness (4). This should then be used for regular monitoring of consciousness level during the care of the sick child. We undertook this audit to identify areas of practice in the national teaching hospital that might need strengthening and to provide a background for the development of standardised protocols for the management of the child presenting with altered consciousness in this setting. For this study we assessed the documentation of both the modified 
Glasgow coma scale and the AVPU scale in the case record review while for the reassessments by the investigator, the modified Glasgow coma scale was used as it is the gold standard.

The objective of the study was to compare actual practice with appropriate recommended standard practice of care specified in Kenyan Ministry of Health guidelines in the year 2000 for children admitted with altered consciousness.

\section{MATERIALS AND METHODS}

This study was carried out at Kenyatta National Hospital (KNH), Kenya between July and October 2005. Ethical approval was obtained from the KNH Ethical Review Committee.

Children were first seen in the paediatric filter clinic (PFC) for initial assessment and emergency management by the clinical staff. As the PFC acts as an accident and emergency service, an appropriate assessment tool would be the Alert, responds to Voice, responds to Pain, Unresponsive (AVPU). They later had a subsequent assessment on the ward by a second clinician as part of the admission procedures on the ward where the appropriate assessment was the modified GCS. This provided us with two sets of documented practice for observation, at PFC and on the admitting ward.

Children presenting with a primary diagnosis associated with altered consciousness wereidentified prospectively over the study period and their case notes were reviewed consecutively. We included records of children aged one month to twelve years presenting with altered consciousness associated with non-traumatic causes and excluded those with a history of traumatic causes of altered consciousness and age less than one month or over 12 years. The standard for assessment of conscious level and appropriate immediate investigations were defined as follows: The AVPU was to be used at the paediatric filter clinic in all children. The modified GCS was to be used by all children presenting with altered consciousness on the ward. A random blood sugar was to be performed on all children presenting with altered consciousness on the filter clinic and / or ward. A lumbar puncture was to be performed on children who fulfilled the criteria set for lumbar puncture. Data were extracted using a pre-coded data collection sheet. The documentation for level of consciousness was collected for the first three days of admission. Documentation of a lumbar puncture examination and random blood sugar were documented at any time first performed during the admission.

In subset of the children whose case notes were reviewed, 43 had a reassessment by the investigator
(PN) using the modified GCS within one hour of the admission clinical assessment by the ward clinician. This was a convenient sample.

In addition to the paediatric wards, twenty clinicians were interviewed who included medical officer interns and senior officers to establish their level of knowledge of assessment of altered conscious states and relevant immediate investigations.

The sample size calculation for the audit, (n $=150$ cases), was calculated by determining what were regarded as clinically relevant exact binomial confidence limits $( \pm 8 \%)$ around a pre-specified proportion $(50 \%)$ using the statistical programme STATA, version 8.0 (STATA Corporation, Texas, USA). The children for the nested reassessment were consecutively recruited and represented a convenient sample.

All data were entered into an Excel spreadsheet and analysed using STATA, version 8.0 (STATA Corporation, Texas, USA). The proportions of children assessed for level of consciousness and the proportions with appropriate investigations were computed and compared to the standards suggested. Appropriate confidence intervals around these proportions were calculated.

\section{RESULTS}

Baseline characteristics in the main group and the sub-group reassessed by theinvestigator were similar (Table 1). Mortality in the record review group was $18 / 170(10.6 \%)$ with majority $(14 / 18)$ of the deaths occurring in the first 72 hours.

Table 1

Baseline characteristics

\begin{tabular}{lcc}
\hline Demographic & $\begin{array}{c}\text { Audit } \\
(\mathrm{n}=170)\end{array}$ & $\begin{array}{c}\text { Reassessment } \\
(\mathrm{n}=43)\end{array}$ \\
\hline
\end{tabular}

Mean Age

(months),

$(95 \%$ CI $) \quad 33(27.6-38.7) \quad 27(15.5-38.6)$

\begin{tabular}{lcc} 
Sex & & \\
$\quad$ Males & $98(57.6 \%)$ & $24(55.8 \%)$ \\
$\quad \begin{array}{l}\text { Females } \\
\text { Days ill before } \\
\text { admission, } \\
\text { mean }(95 \% \text { CI })\end{array}$ & $62(42.4 \%)$ & $19(44.2 \%)$ \\
Mortality & $18(10.6 \%)$ & $4(1-16)$ \\
\hline
\end{tabular}

NB: The reassessment group is a subset of the case record review group 
Overall the documented assessment of level of consciousness using standard scores was very low (Table 2). Documented use of the rapid assessment scale (AVPU) was less than $10 \%$ at PFC with no use of the formal coma scale here. The documented use of formal coma scales (modified GCS) on admission to the ward was very low at $8 \%$, rising to $21.7 \%$ if either a GCS or AVPU were recorded. Majority of patients (74.7\%) had only descriptive comments characterising their level of consciousness. Descriptive comments included drowsy $(17 \%)$, dull (17\%), irritable $(15 \%)$ and lethargic $(25 \%)$ in the majority of cases.

Table 2

Recognition and grading of level of consciousness

\begin{tabular}{|c|c|c|c|c|}
\hline & $\begin{array}{c}\text { Comment } \\
\text { on level of } \\
\text { onsciousness } \\
\text { No. }(\%)\end{array}$ & $\begin{array}{l}\text { AVPU } \\
\text { No. }(\%)\end{array}$ & $\begin{array}{c}\text { GCS } \\
\text { No. }(\%)\end{array}$ & $\begin{array}{c}\text { Descriptive } \\
\text { comment } \\
\text { No. }(\%)\end{array}$ \\
\hline $\begin{array}{l}\mathrm{PFC}(\mathrm{n}=170) \\
\text { Admission }\end{array}$ & 0) $17 \quad 10$ & $169.4^{*}$ & - & 13780.5 \\
\hline $\begin{array}{l}(\mathrm{n}=170) \\
\text { Day } 1\end{array}$ & $\begin{array}{ll}6 & 3.5\end{array}$ & $2313.5^{*}$ & $148.2^{*}$ & $127 \quad 74.7$ \\
\hline$(n=160)$ & $44 \quad 27.5$ & $3521.8^{*}$ & $127.5^{*}$ & $\begin{array}{ll}69 & 43.1\end{array}$ \\
\hline $\begin{array}{l}\text { Day } 2 \\
(n=156)\end{array}$ & $64 \quad 41$ & $4931.4^{*}$ & $63.8^{*}$ & $\begin{array}{ll}37 & 23.7\end{array}$ \\
\hline
\end{tabular}

$\mathrm{PFC}=$ paediatric filter clinic. Admission, day 1 and 2 assessments were all on the paediatric wards.

${ }^{*}$ Formal assessments of consciousness used.

A comparison of the descriptive terms to standard formal assessments of consciousness (Table 3) showed wide variation demonstrating their limited value as specific medical information. There was no relation between the descriptive terms used when compared with the modified Glasgow coma scores given on reassessment except in the case of "coma" and "semi-coma".

\section{Table 3}

Comparison of descriptive comments of level of consciousness versus Glasgow Coma Score (GCS) assessment

\begin{tabular}{lc}
\hline Description of consciousness & GCS range \\
\hline Coma $(\mathrm{n}=\mathrm{l})$ & 4 \\
Semi coma $(\mathrm{n}=1)$ & 6 \\
Drowsy $(\mathrm{n}=7)$ & $8-14$ \\
Irritable $(\mathrm{n}=10)$ & $6-13$ \\
Lethargic $(\mathrm{n}=10)$ & $7-13$ \\
Conscious $(\mathrm{n}=6)$ & $8-14$ \\
Normal $(\mathrm{n}=1)$ & 8 \\
\hline
\end{tabular}

Relevant immediate investigations performed were blood slide for malaria $(89.4 \%$ ) where $13 \%$ were read as positive, random blood glucose $(32.9 \%)$ where hypoglycaemia was noted in one child and lumbar puncture $(32.9 \%)$ for cerebrospinal fluid analysis where four samples were positive for organisms. The organisms isolated were Haemophilus influenzae $(\mathrm{n}=1)$, Streptococus pneumoniae $(\mathrm{n}=2)$ and gram positive $\operatorname{cocci}(\mathrm{n}=1)$

A convenience sample of twenty clinicians was interviewed and all reported knowing about the GCS. Eighteen of twenty clinicians knew the correct range for the GCS. However we did not test their ability to use the score. Most of the clinicians also demonstrated appropriate knowledge of relevant immediate investigations which we determined as the random blood sugar and lumbar puncture for a child with non-traumatic altered consciousness.

\section{DISCUSSION}

A state of altered consciousness is not a common feature in children at presentation. The criterion for significant neurological dysfunction in paediatric cases with severe illness is a GCS less than or equal to eleven or an acute change in mental status with a decrease in GCS greater than or equal to three points from an abnormal baseline (5).

At the paediatric filter clinic (PFC), (Table 2) no use of the Glasgow Coma Scale was documented during the study period. The formal scale used was the AVPU scale in 9\% of children's records reviewed. Majority ( $n=137)$ had other descriptive comments to provide a clinical indication of their level of consciousness. On the admitting ward, the Glasgow Coma Scale was used in $8 \%$ of new admissions with altered consciousness. Overall formal coma scale use, including AVPU, was 22\% at the ward level where admissions are supposedly thoroughly evaluated by doctors.

As at the PFC the remainder had only a descriptive comment on their level of consciousness. This level of documentation was similar to a prospective audit in 100 adults in the UK where despite guidelines for the use of the GCS in the NICE guidelines, $66 \%$ did not have a neurological observations prescribed, only a further $12 \%$ had correct observations prescribed and only $1 \%$ had complete observations documented (6). Similarly a retrospective audit of children with head injury showed that out of 14 children, only one had complete neurological observations documented (7).

Poor use of assessment scales was despite high levels of knowledge surrounding these scales. While reasons for this anomaly were not 
specifically investigated some PFC clinicians' comments suggested high workloads and lack of time contributed to failure to use a formal assessment scale while we speculate that lack of implementation of practice guidelines may also be a major contributor.

Although descriptive assessments of consciousness level were commonly used, the correlation between these descriptions and the standard GCS scores was very poor (Table 3). These descriptive terms thus convey little valuable clinical information and are almost certainly of little value in monitoring disease progression or resolution.

Amongst children with clear indications for simple investigations to establish the cause for altered consciousness and / or assist in its treatment only a blood slide is commonly performed. A random blood sugar is performed in only half and an appropriately timed lumbar puncture (LP) in less than $10 \%$. Only two children $(1.2 \%)$ had all three relevant assessment performed: GCS assessment, LP and a RBS performed. A recent review showed that physicians did not follow practice guidelines for reasons linked to barriers in knowledge, attitudes and behaviour (8). While these findings may be directed at the $\mathrm{KNH}$, similar findings have been shown in other surveys of district hospitals (9).

In summary, this audit shows that while clinical teaching in neurology includes the assessment of level of consciousness using the GCS this approach is rarely used in practice. Simple investigations are often not performed. These findings show a need to define and implement standard management guidelines in $\mathrm{KNH}$ which may help improve the quality of care. We recommend the implementation of evidence based guidelines for the management of children presenting with altered consciousness with regular audits to ensure adherence by the staff to the guidelines.

\section{ACKNOWLEDGEMENTS}

This work was partially supported by the KEMRI -Wellcome Trust Research Programme. We would like to thank Prof. R. Nduati and Dr. E. Obimbo for their comments. The staff in the Paediatric Filter Clinic and paediatric wards of Kenyatta National Hospital for their involvement in the interviews and the patients who were involved in these assessments. This work has been published with the permission of the Kenyatta National Hospital Ethics Review Committee.

\section{REFERENCES}

1. Berkley, J. A., Ross, A., Mwangi, I., Osier, F. H., et al. Prognosticindicators of early and late death in children admitted to district hospital in Kenya: cohort study. Brit. Med. J. 2003; 326: 361.

2. Grant, I. S. and Andrews, P. J. ABC of intensive care: neurological support. Brit. Med. J. 1999; 319: 110-113.

3. Kirkham, F. J. Non-traumatic coma in children. Arch. Dis. Child. 2001; 85: 303-312.

4. Government of Kenya. Coma in Clinical Guidelines for the diagnosis and treatment of common conditions in Kenya. pages 255-256. Second ed. Nairobi; Ministry of Health. 2002.

5. Jennett, B. Predicting outcome after head injury. J. $R$. Coll. Physicians Lond. 1975; 9: 231-237.

6. Qureshi, A. A., Mulleady, V., Patel, A. and Porter, K. M. Are we able to comply with the NICE head injury guidelines? Emerg. Med. J. 2005; 22: 861-862.

7. Kay, A. and Teasdale, G. Head injury in the United Kingdom. World J. Surg. 2001; 25: 1210-1220.

8. Cabana, M. D., Rand, C. S., Powe, N. R., et al. Why don't physicians follow clinical practice guidelines? A framework for improvement. J. Amer. Med. Assoc. 1999; 282: 1458-1465.

9. English, M., Esamai, F., Wasunna, A., et al. Assessment of inpatient paediatric care in first referral level hospitals in 13 districts in Kenya. Lancet. 2004; 363: 1948-1953 